\title{
Involuntary urine loss: Dispelling the myths
}

\section{MARGARET REICH \\ Senior Staff Editor}

In an age when condoms as barriers against the human immunodeficiency virus (also known as the AIDS virus) are the subject of daily public service announcements, you would think society had broken the last taboo. Not true. Somewhere between 7 and 12 million Americans, many of whom are elderly, silently and needlessly suffer from urinary incontinence- - the inability to voluntarily control urine loss.

Changing the misperceptions about this widespread problem begins with the understanding that urinary incontinence is not a disease, but a symptom of some underlying disorder. It is not an inevitable aspect of aging. Most of all, it can be treated and more often than not, cured.

While incontinence generally involves difficulty in storing, and less commonly, releasing urine, physicians usually classify it according to four types. More than one can occur simultaneously, however. The characteristics of each vary; representative features are noted below. Keep in mind that only a physician can determine which, if any, you may have.

Stress

Not to be confused with an emotional state, stress incontinence, like most other types, predominantly affects women. This most common display of incontinence ensues when intra-abdominal pressure increases. Laughing, coughing, sneezing, lifting heavy objects, or even jogging puts extra strain on these stomach muscles. The bladder reacts by uncontrollably releasing urine. Weakened pelvic floor muscles are considered a prime suspect here.

\section{Urge}

Sometimes accompanying stress incontinence, urge features a strong need to relieve yourself. A few seconds or minutes later involuntary leakage occurs, usually before you reach the toilet. Nighttime bedwetting can be expected. An overactive or unstable bladder muscle due to damage in the central nervous system may be responsible. This kind of incontinence can be one symptom of Alzheimer's disease, a brain tumor, Parkinson's disease, or stroke.

\section{Overflow}

Losing small amounts of urine despite frequent trips to the commode may signal overflow incontinence. Someone with this problem usually strains while voiding and even then the bladder never feels completely empty. Diabetes or a lack of $B_{12}$ are just a few things that might produce neurological malfunctions or an obstruction in the urinary tract that would prompt overflow.

\section{Reflex}

Maybe the most difficult type to diagnose, reflex incontinence usually points to major neurological damage. For example, a tumor on the spinal cord prevents the bladder from sensing when it's full and needs to be emptied. Leakage occurs without warning anytime during the day or night.

\section{Admitting it exists}

Perhaps the trickiest part of diagnosis is simply getting the patient, and in some instances even the physician, to address the problem. According to statistics compiled by Help for Incontinent People (HIP), only 1 in 12 ever seeks medical assistance. Embarrassment plays a major role in the reluctance to discuss the problem with a doctor. Fear of being put in a nursing home because of this disorder cannot be overlooked, either. In fact, more than $50 \%$ of nursing home residents are incontinent. 


\section{No age boundaries}

Seniors, take comfort. You are not alone with this problem. HIP statistics indicate that $53 \%$ of women pregnant with their first child experience some loss of urine control. Even women who have never been pregnant can face uncontrollable urine loss. Ten percent of 6-year-old children still wet themselves.

Anatomical differences partly explain why more women than men suffer with this problem. Pelvic floor muscles lose elasticity after childbirth. But motherhood is not the only culprit. Obesity and the internal organs' constant struggle against gravity share responsibility for lax muscles. Similarly, postmenopausal estrogen deficiency can affect muscle control in the lower urinary tract.

Generally men, particularly those younger to earlymiddle aged, seem less incontinent-prone primarily because their anatomical structure features two well defined sphincters, one at the base of the bladder and an external one. These muscles open and close the bladder. The male urethra, the internal tube that carries urine to the outside of the body, is longer and therefore less subject to bacterial infection than women's. Furthermore, women have only one internal sphincter.

It's not all smooth sailing for men, though. With age the prostate gland, which surrounds the neck of the bladder and urethra, slowly enlarges. This enlargement causes the urethra to narrow and may eventually obstruct urine flow completely.

As such, it's important that men over age 40 have an annual rectal examination to check for any abnormal growths or prostate infections. Most prostate difficulties, including obstruction, rarely surface until age 60 , if at all. If an obstructed prostate is the problem, surgery is usually necesary. In some cases, such surgery can induce urinary incontinence. However, an additional operation can correct it.

\section{Contributing factors}

Regardless of sex, certain factors associated with the aging process cannot be ignored. Bladder capacity and elasticity are thought to decrease as does urethra length. While these alone do not cause urinary incontinence, they put the lower urinary tract at risk for infections, a sign of which can be urinary incontinence.

When and how often urination takes place differs between younger and older folks. Younger people void earlier during the day. But for the elderly, waking up in the middle of the night to use the bathroom is normal and does not necessarily indicate urinary incontinence.

However, more frequent urination can cause accidents if some other ailment prevails. For example, an elderly person who has trouble moving about may not reach the bathroom in time. Likewise, someone with Alzheimer's disease or with early dementia may not be aware of the need to urinate. Such a person may even forget how to unfasten clothes once reaching the toilet.

\section{Medicines complicate the issue...}

Certain prescription and over-the-counter drugs can aggravate the bladder or affect the nervous system. Water pills, antihistamines, cold remedies, sedatives, laxatives or antidiarrheal agents should be used with caution. In particular, the latter contribute to constipation, an often overlooked, but important factor in involuntary urine loss. While the reasons for this are not fully understood, impacted feces may place stress on the bladder.

\section{...but keeping a record helps}

Before that first appointment with your physician, note what medications you take, even those that seem unrelated to the problem. In addition, keep track of when accidents happen as well as regular voiding patterns. If possible gauge how much urine is lost each time by the number of pads or undergarments changed daily.

With this information, a physician can begin to assess whether or not the situation is actually incontinence, and if so what type. Final diagnosis depends on results from tests designed to recreate the leakage. For example, to rule out stress incontinence, your physician may press against the bladder while you cough, or have you gradually sit up from a prone position to increase abdominal pressure. Many tests can be performed in the doctor's office.

\section{Working toward a solution}

Treatment is as varied as the causes. Minor incontinence may resolve simply by reducing fluid intake. If stress incontinence is the culprit, pelvic 
exercises designed to strengthen muscles by contracting them and stopping urine in midstream may be prescribed. When incontinence accompanies irritation due to vaginal dryness, estrogen replacement therapy may be helpful. Likewise, weight loss can be a viable option in certain cases.

Bladder training that involves changing toilet habits provides another option. Using your diary as a guide, your physician will establish voiding patterns at scheduled intervals. Time in between trips to the bathroom is gradually increased or shortened depending on the individual. Bladder capacity should increase with training. Making a mad dash for the bathroom only puts more pressure on the intraabdominal muscles, creating more stress. Therefore, learning not to respond hurriedly to the voiding urge must be mastered, too.

A relatively new approach to incontinence, biofeedback teaches you to recognize and control muscle contractions until you can reach the commode. This technique works best with a motivated, alert person with a normal nervous system.

In conjunction with these nonpharmaceutical methods, medicine may be prescribed to enhance muscle control of the bladder. Because these drugs affect other muscles in the body besides the bladder, physicians dispense them with caution. Likewise, while surgery may be necessary to repair certain types of incontinence, it is usually the last resort. As in other medical instances, get a second opinion before agreeing to any surgical procedure.

\section{The diaper dilemma}

While the previous treatments should be part of a physician-supervised treatment program, too often diapers are used as a "quick fix" in lieu of a trip to the doctor's office. By themselves, these products fail to address the real cause(s) of the problem. They foster a sense of low self-esteem, and may serve to condone involuntary urine loss as normal, acceptable behavior.

Other management techniques should be attempted before relying on diapers. Just rearranging the furniture for a clear path to the bathroom can prevent accidents. Make sure the bathroom is a safe place. Handles or grab bars offer added security. Adjust the toilet seat height for easier access. Finally, if unfastening clothes presents a problem, replace buttons and zippers with Velcro ${ }^{\circledR}$.

Of course these suggestions are feasible only when you're able to move around. Bedridden or incognitive persons may have to wear a diaper. In such instances, scrupulous skin care becomes paramount. The caregiver should use cleansing products specifically intended for incontinence. These are available at home health care stores. General use wipes and the like, sold at drug stores, contain alcohol and other ingredients that play havoc with an older person's delicate skin. Lanolin and other emollients that are absorbed beneath the surface are part of a healthy skin care regimen.

\section{Last minute suggestions...}

As always, diet plays a key role in maintaining overall good health. Certain foods and drinks may aggravate the bladder, although their specific actions are not fully understood. Nonetheless, stay away from coffee (even decaffeinated) and other caffeine-laden beverages. Opt for water, grape, cranberry, cherry, or apple juice.

Stop smoking! Not only does it irritate the bladder surface, but it can cause bladder cancer.

Women, young or old, incontinent or not, should practice pelvic muscle exercises daily. Ask your doctor to explain how these are done.

Relieve your bladder frequently. Make sure it's completely empty each time. Above all, seek professional care if you are experiencing leaking in any amount.

Stop believing the myths and start living continent again. For more information, send a stamped business-size, self-addressed envelope to: Help for Incontinent (HIP), P.O. Box 544, Union, SC 29379, or call (803) 585-8789.

(All material in the Patient Health Guide is reviewed by JAOA physician referees.)

\section{References:}

The American Medical Association Family Medical Guide. Edited by Jeffrey R.M. Kunz and Asher J. Finkel. Random House, Inc., New York, 1987, p 586.

Bladder training and related therapies for urinary incontinence in older people. By Evan C. Hadley. Journal of the American Medical Association, vol 256, pp 372-379, July 18, 1986 
Cancer facts \& figures-1987. American Cancer Society, New York, 1987.

Causes of female incontinence. By Yair Walzer. Postgraduate Medicine, vol 83, pp 78-88, May 15, 1988.

Help for Incontinent People (HIP) (media kit), Union, SC, 1987.

Loss of bladder control: Your guide to treatment options. HIP, Union, SC, 1987.

"The last of the closet issues." by Anastasia Toufexis. Time, vol 128, p 69, Oct 6, 1986

Management of urinary incontinence in the elderly. By Neil M. Resnick and Subbarao V. Yalla. The New England Journal of Medicine, vol 313. pp 800-805, Sept 26, 1985.

New issues in geriatric care. By Herbert C. Sier. Annals of Internal Medicine vol 108, pp 720-724, May 1988.

Obscuring urinary incontinence: Diapering of the elderly. By Perry Starer and Leslie S. Libow. Journal of the American Geriatrics Society, vol 33, pp 842-845. Dec 1985.
Surgeon General's report on acquired immune deficiency syndrome. U.S Department of Health and Human Services. The Journal of the American Osteopathic Association, vol 87, p 105, Jan 1987.

Urinary incontinence in the elderly. By Neil M. Resnick. Hospital Practice, vol 21, pp 80C-80Z, Nov 15, 1986

Urinary incontinence in the elderly. By Diane G. Snustad and I. Thomas Rosenthal. American Family Physician, vol 32, pp 182-196, Nov 1985.

Urinary incontinence in the elderly: Ways to relieve it without surgery by John G. Gregory and Michaela H. Purcell. Postgraduate Medicine. vol 80 , pp. 253-262, Aug 1986

When the patient is incontinent. By Harold A. Fuselier, Robert T. Plumb, Stephen N. Rous, et al. Patient Care, vol 19, pp 49-65, Jan 30, 1985

When the problem is incontinence. By lerry G. Blaivas, Shlomo Raz, Nei M. Resnick, et al. Patient Care, vol 22, pp 69-98, Jan 15, 1988 


\section{American Osteopathic Association \\ Continuing Medical Education}

\section{CERTIFICATION OF HOME STUDY}

This is to certify that I,

activity for AOA CME credits.

completed the following

Please print

Type of activity (such as reading or listening)

Vame of journal(s) or audio-tape and date(s) of issue(s):

(One-half CREDIT may be granted for each issue or tape)

MAIL TO: AOA Division of CME, 142 East Ontario Street, Chicago, Illinois 60611

KEEP A DUPLICATE FOR YOUR RECORDS!

The Home Study form is intended to document individual reading of recognized scientific journals, listening to approved audio-tapes, and other approved home study courses and programs under the criteria described for Category 2-B.

Only one type of home study, such as reading, should be indicated on a single form, though multiple issues of scientific journals may be listed.

This form should not be used, however, when CME quiz cards for the AOA Journal are submitted separately.

\begin{tabular}{|l|}
\hline FOR OFFICE USE ONLY \\
\hline Cat. $\_$2-B Credits__ \\
Program $\#$ \\
Doctor \# \\
Doctor's Name \\
\hline
\end{tabular}




\section{Together We Can MaKe A Difference}

Recognizing the need to market their practices locally, many DOs have asked for a professional black-and-white ad that can be used in their community newspapers. Now you can have either or both of the ads on these pages free if you are an AOA member or affiliate, or for $\$ 25$ each if you aren't. We'll provide the ads, ready to have your name and address inserted in the box at the bottom; you pay for the space. Show the sample to your paper, get the space charges, then request camera ready copies from the AOA Public Relations Department.

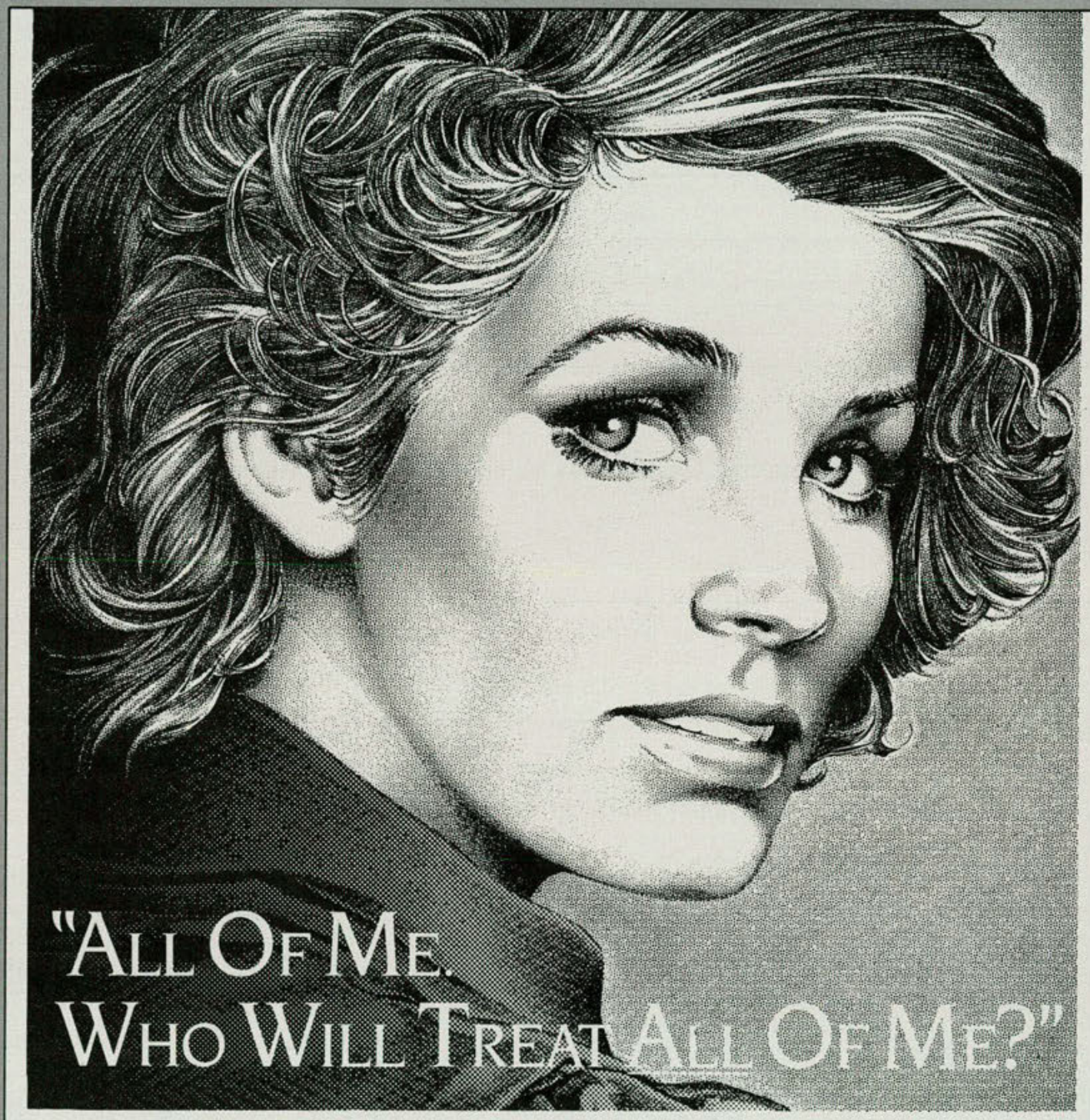

You sometimes wonder-we know you do - whether any physician has ever viewed you as a whole person, with needs that extend beyond the part of you that hurts. Emotional. Nutritional. Physiological needs. One specific type of doctor, the Osteopathic Physician, is qualified to care for all of you. For every aspect of you as a personyour physical well-being, emotional health, your nutritional needs, and those of every member of your family.

It's reassuring to know that in this world of fragmented medical care, someone still cares for all of you.

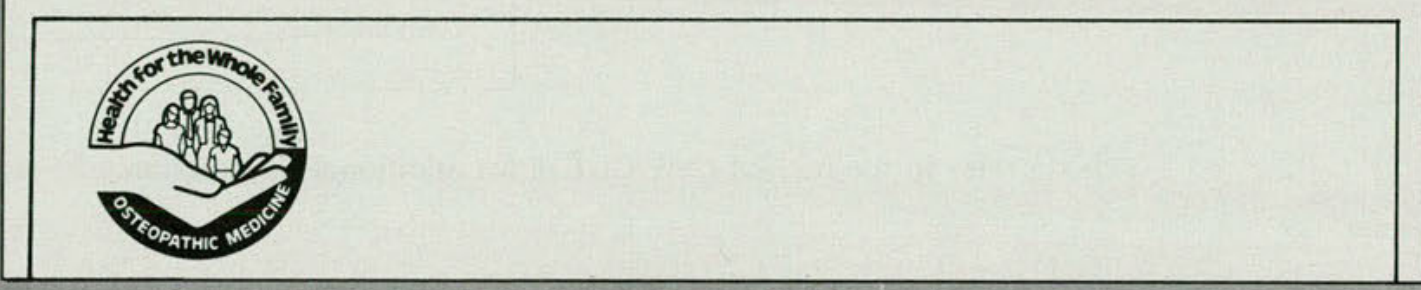


THERE IS

A DOCTOR FOR ALL OF

YOU.

\section{BYEDUCATION,} TRAINING, AND CHOICE.

One specific type of physician is qualified to care for all of you. To care for every aspect of you as a person-your physical well-being, emotional health, your nutritional needs, and those of every member of our family.

An Osteopathic Physician is a family oriented doctor-a general practitioner or other specialist-someone who recognizes you as a person with needs that extend beyond the part of you that hurts on any given day.

It's good to know that in this world of fragmented medical care, someone still cares for all of you.
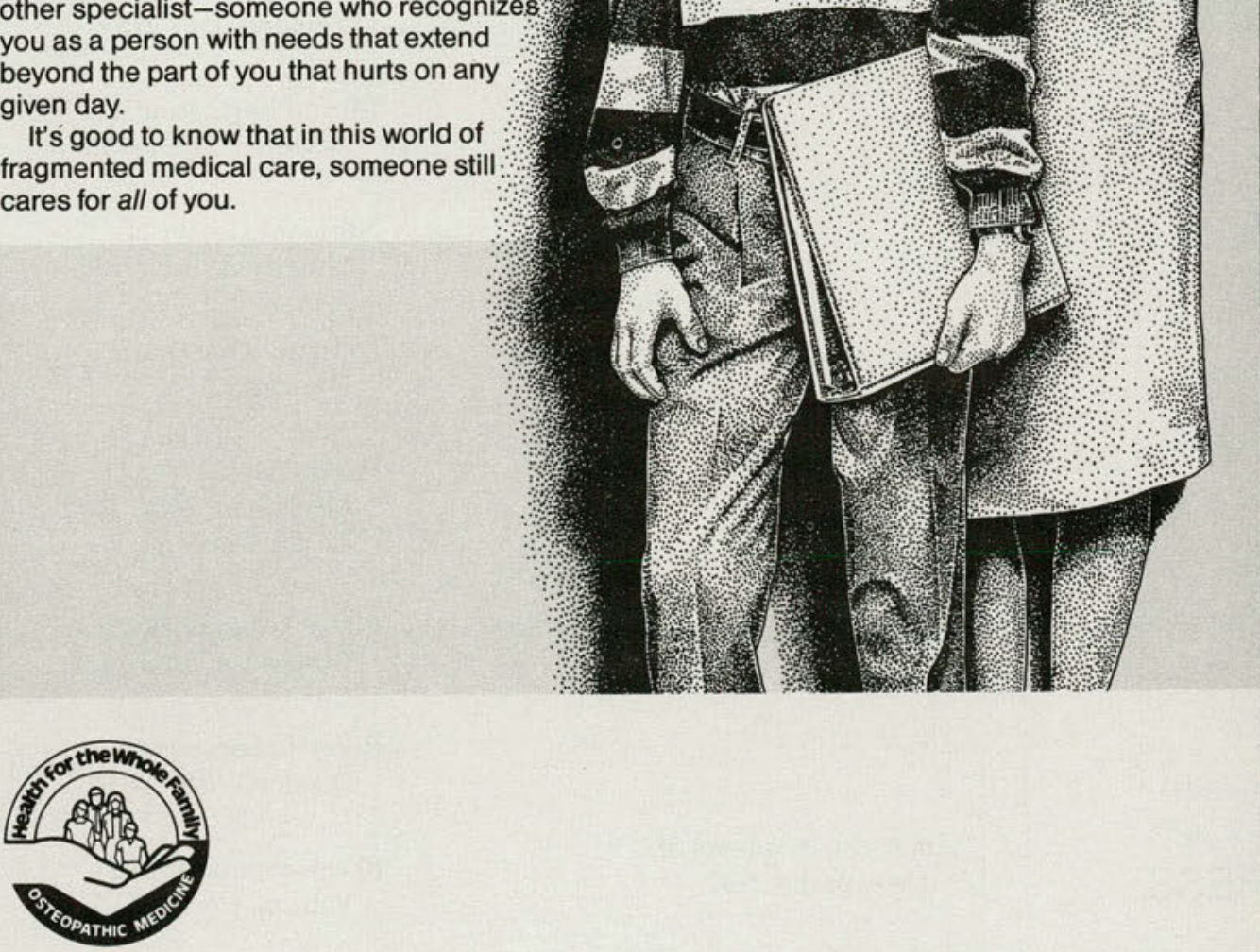

\section{Together We Are Making A Difference}

The ads are offered courtesy of the Auxiliary to the American Osteopathic Association and the AOA, free or at nominal cost. They are part of the national ad campaign initiated by the AAOA, which will also include some color ads in national magazines. The costs are covered by contributions to the Auxiliary, so if you would like to help it to continue the program, please send your contribution to the National Ad Campaign, Auxiliary to the AOA, 142 E. Ontario St., Chicago, IL 60611. 